\title{
Original
}

\section{Molecular Forms of Cholecystokinin in Human Bile in Patients with Obstructive Jaundice}

\author{
Akira Takahashi, Shigeki TanaKa, Hitoshi Yoshida, Susumu NaKamata, \\ Fumihiko Nozu, Ikuta NaKano, Katsuya Kitamura, Tsunao Imamura, \\ Akitoshi IKegami, Junichi Nirkawa and Keiji Mitamura
}

\begin{abstract}
Cholecystokinins (CCKs) in extracts of human bile of patients with obstructive jaundice were compared with those in bile of patients without obstructive jaundice. Cholecystokinins were purified from human bile using chloroform with a Sephadex G-25 column and a Sep-Pak $\mathrm{C}_{18}$ cartridge and isolated by high performance liquid chromatography (HPLC). The different molecular forms of cholecystokinin (CCK), especially cholecystokinin tetrapeptide (CCK-4), cholecystokinin octapeptide (CCK-8) and cholecystokinin triacontatriapeptide (CCK-33) in human bile were isolated by HPLC and measured by radioimmunoassay and bioassay. The concentrations of CCK measured by radioimmunoassay (RIA) were consistent with those by bioassay, indicating that bioactivity of CCK is not attenuated in human bile. Moreover, the CCK receptor antagonist L-364,718 (10 nM) completely inhibited the bioactivity of CCK in human bile. We found that the predominant molecular forms of the CCK in human bile of patients with obstructive jaundice are larger than those in bile of patients without obstructive jaundice. These results suggested that the liver may be the major site of CCK extraction or degradation and may therefore play a significant role in CCK turnover.
\end{abstract}

Key words : cholecystokinin, human bile, molecular forms, obstractive jaundice, radioimmunoassay, bioassay

\section{Introduction}

Cholecystokinin (CCK) is a regulatory hormone that stimulates pancreatic exocrine secretion and gallbladder contraction. In 1968, Mutt and Jorpes isolated CCK, a polypeptide composed of 33 amino acids from the upper small intestinal mucosa of pig ${ }^{1)}$. Subsequently several molecular forms of CCK, including CCK-58, CCK-39, CCK-33, and CCK-8, were characterized in intestinal and brain extracts from several species of mammals ${ }^{2-5)}$. L-364,718, a synthetic benzodiazepine derivative, was recently shown to be a potent nonpeptide CCK receptor antagonist which selectively inhibits CCK receptors in peripheral tissues ${ }^{6,7)}$.

Hepatic CCKs have been characterized in several species ${ }^{8-11)}$. A number of circulating hormones including insulin ${ }^{12)}$, epidermal growth factor (EGF) ${ }^{13)}$, pentagastrin ${ }^{14)}$ and $\mathrm{CCK}^{8,11)}$, are rapidly excreted from the hepatocyte in bile in both intact and metabolized labeled

Second Department of Internal Medicine, Showa University School of Medicine, 1-5-8 Hatanodai, Shinagawa-ku Tokyo 142-8666, Japan. 
forms. The distribution of the various molecular forms of CCKs in human bile is not known. Since purification was incompletely performed, interfering substances and cross reactive compounds may have affected levels of CCKs measured by radioimmunoassay and CCK bioactivities in human bile. Indeed, CCKs in human bile have not been extracted, and those could not have been measured by RIA and bioassay. Plasma CCKs have been measured by RIA using anti-CCK antiserum, OAL-656, or by bioassay of rat pancreatic acini $^{15-17)}$ in recent years.

There has been some controversy in previous studies ${ }^{8,11,19-21)}$ regarding the metabolism and elimination of CCK through the liver and kidney. Thompson et al. ${ }^{20)}$ demonstrated that the kidney is a major site for uptake of CCK-33. CCK is quickly degraded from the blood circulation and $59 \%$ of CCK-8 was extracted in a single pass through the liver ${ }^{8)}$, indicating that the liver is a major site for uptake of CCK- $8^{8,19,20,22)}$. Himeno et al. ${ }^{21)}$ demonstrated that fasting plasma CCK levels in patients with liver cirrhosis were significantly higher than those in patients with renal failure and those in normal subjects. Miyasaka et al. ${ }^{23)}$ reported potentiated bioactivities of plasma CCKs in patients with obstructive jaundice, choledocolithiasis and primary biliary cirrhosis. We also demonstrated ${ }^{24)}$ that plasma CCK levels in patients with obstructive jaundice were significantly higher than those in normal subjects and that plasma CCK gradually decreased after percutaneous transhepatic cholangio drainage (PTCD). Based on these results, we predicted that the distribution of molecular forms of CCKs might be altered in human bile of patients with obstructive jaundice.

The aims of the present study were to investigate whether purification could retain the bioactivity of isolated CCK in human bile and to elucidate the distribution of the various molecular forms of CCKs in bile of patients with and without obstructive jaundice.

\section{Subject and Methods}

\section{Materials and Chemicals}

Methanol, trifluoro acetic acid (TFA), chloroform and barbital sodium were purchased from Wako Pure Chemical Industries, Ltd. (Tokyo, Japan). Centri Cell (centrifugal ultrafilter, 10000NMWL) from ABI, Inc. (Urayasu, Chiba, Japan). Sep-Pak $\mathrm{C}_{18}$ cartridge was purchased from Waters (Millford, MA, USA). ${ }^{3} \mathrm{H}-\mathrm{CCK}-8,{ }^{125} \mathrm{I}-\mathrm{CCK}-8$ were purchased from Amersham Japan (Tokyo, Japan). ${ }^{125}$ I-CCK-33 was purchased from Otsuka Pharmaceutical Co., Ltd. (Tokushima, Japan). Sephadex G-25 super fine was purchased from Pharmacia (Uppsala, Sweden). L-364,718 was obtained from Merc Sharp \& Dohme Research Laboratories (West Point, PA, USA).

\section{Peptides}

Cholecystokinin tetrapeptide (CCK-4), cholecystokinin octapeptide (CCK-8, sulfated form) and cholecystokinin triacontatriapeptide (CCK-33, human) were purchased from Peptide Institute, Inc. (Osaka, Japan).

\section{Subjects}

Bile samples were obtained by trough PTCD from three patients with obstructive jaundice caused by cholangioma and gallbladder carcinoma, and collected via $T$-tube from one patient without obstructive jaundice after cholecystectomy. These three patients, one male and two females, were 76 to 84 years of age $($ mean $=79.3)$. One female patient without 
obstructive jaundice was 68 years old and was included as a control. Informed consent was obtained from all patients. Plasma total and direct bilirubin were 18.1 (14.9), 24.7 (19.9), $8.8(6.9)$ and $0.7(0.3) \mathrm{mg} / \mathrm{dl}$ in each patient, respectively. Bile samples were immediately frozen and stored at $-20^{\circ} \mathrm{C}$ until CCK extraction.

Extraction and purification of cholecystokinins from human bile

\section{Extraction}

Frozen bile was boiled for $10 \mathrm{~min}$ and centrifuged at $15,000 \mathrm{rpm}$ for $30 \mathrm{~min}$ at $4{ }^{\circ} \mathrm{C}$. The supernatant was shaken with chloroform at $180 \mathrm{rpm}$ for $10 \mathrm{~min}$ and centrifuged at 3,000 rpm for $10 \mathrm{~min}$ at $4^{\circ} \mathrm{C}$. The recovery rate of ${ }^{3} \mathrm{H}-\mathrm{CCK}-8$ was $85.8 \pm 1.8 \%$ (mean $\pm \mathrm{SD}$ ). After shaking with chloroform (five times), bile was centrifuged at $4,000 \mathrm{rpm}$ for $30 \mathrm{~min}$ at $4^{\circ} \mathrm{C}$ using a CentriCell.

\section{Chromatographic analysis}

One milliliter of bile was loaded onto a Sephadex G-25 column $(2.0 \times 15 \mathrm{~cm})$ and eluted with $20 \mathrm{mM}$ barbital buffer $(\mathrm{pH} 8.0)$ at a flow rate of $10 \mathrm{ml} / \mathrm{hr}$. Five-milliliter fractions were collected and fractions 10 to 25 were concentrated on a Sep-Pak C18 cartridge before HPLC. The column was calibrated with ${ }^{125} \mathrm{I}-\mathrm{CCK}-8$ and ${ }^{125} \mathrm{I}-\mathrm{CCK}-39$.

\section{Purification}

Sep-Pak $\mathrm{C}_{18}$ cartridges were washed with $5 \mathrm{ml}$ of methanol and $10 \mathrm{ml}$ of distilled water, and loaded with $5 \mathrm{ml}$ of eluate using a Sephadex G-25 column as described above. After the cartridges were washed with $10 \mathrm{ml}$ of distilled water, samples were eluted with $2 \mathrm{ml}$ of $50 \%$ acetonitrile and then lyophilized. The recovery rates of ${ }^{125} \mathrm{I}-\mathrm{CCK}-8$ and ${ }^{125} \mathrm{I}-\mathrm{CCK}-39$ were $83 \pm 0.2 \%$ and $71.4 \pm 4.1 \%$, respectively.

\section{High performance liquid chromatography analysis}

HPLC analysis was performed on a TOSOH HPLC system (TOSOH Co., Ltd. Tokyo, Japan). The diluted eluates from the Sep-Pak $\mathrm{C}_{18}$ cartridges were applied to a HPLC column (TOSOH, TSK gel Octadecyl-NPR, $4.6 \mathrm{~mm}$ I.D. $\times 3.5 \mathrm{~cm}$ or $4.6 \mathrm{~mm} \mathrm{I.D.} \times 10 \mathrm{~cm}$ ). The samples were dissolved in $1 \mathrm{ml}$ of buffer B $(0.05 \%$ TFA), and a $100 \mu 1$ aliquot was injected, and eluted with a gradient of $0-50 \%$ buffer B on a $4.6 \mathrm{~mm}$ I.D. $\times 3.5 \mathrm{~cm}$ column for $30 \mathrm{~min}$, or on a gradient of $0-50 \%$ buffer B on a $4.6 \mathrm{~mm}$ I.D. $\times 10 \mathrm{~cm}$ column for 30 min. The elution rate was $1 \mathrm{ml} / \mathrm{min}$, and $1 \mathrm{ml}$ of collected fractions was evaporated under nitrogen. The HPLC columns were calibrated with synthetic peptides, CCK-4, sulfated CCK-8 and human CCK-33. The recovery rates of CCK-8 and CCK-33 by adding 100 pmol of each peptide without bile were $80-90 \%$ and $70-80 \%$, respectively.

\section{Bioassay}

Dispersed pancreatic acinar cells were prepared by a modification of the method of Gardner and Jackson ${ }^{17)}$. Male Wistar rats ranging from 150 up to $200 \mathrm{~g}$ were obtained from Saitama Jikken Dobutsu (Saitama, Japan). The animals were kept at $22^{\circ} \mathrm{C}$ on a $12-\mathrm{hr}$ light and dark cycle. The pancreas was removed after a 12-hr fast, and injected with 600 Units collagenase (Type 4, SIGMA, St. Louis, MO, USA), and suspended in $5 \mathrm{ml}$ of modified Krebs-Ringer HEPES (KRH) buffer, containing $22 \mathrm{mM}$ HEPES and $0.16 \%$ 


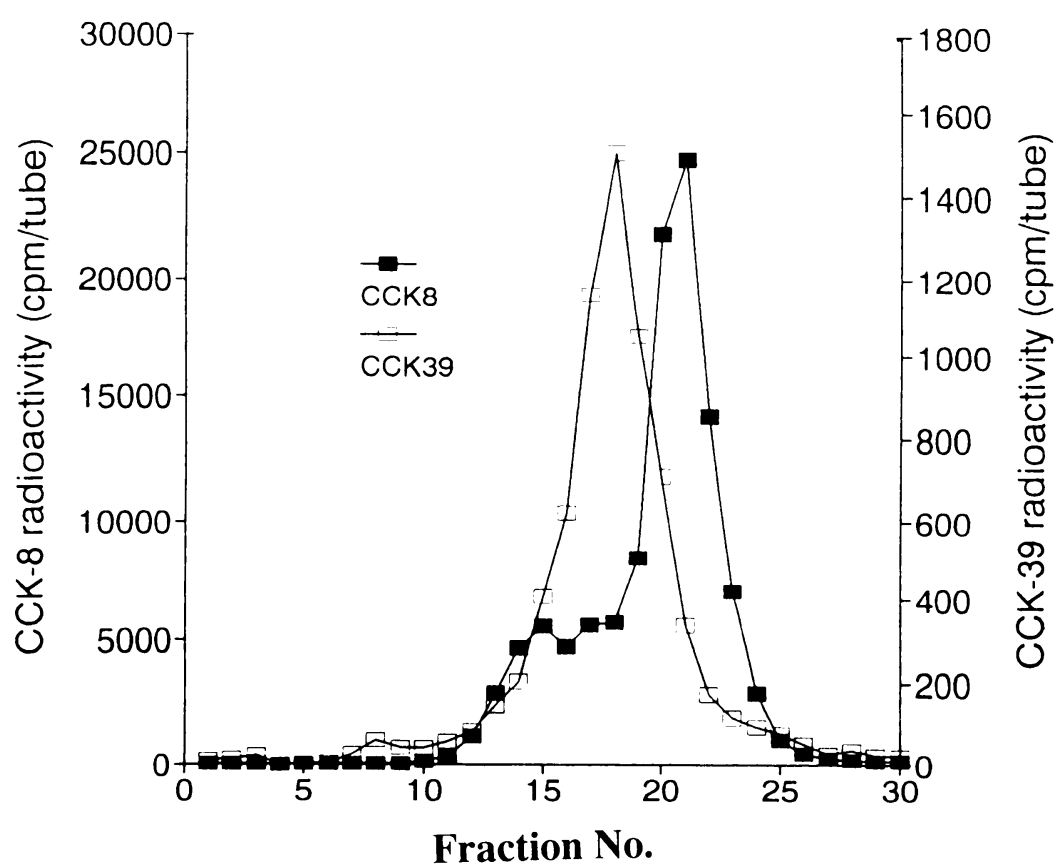

Fig. 1 Sephadex G-25 column elution profiles of ${ }^{125}$ I-CCK-8 and ${ }^{125}$ I-CCK-39.

$(\mathrm{W} / \mathrm{V})$ bovine serum albumin (BSA). All solutions were adjusted to $\mathrm{pH} 7.4$ at $37^{\circ} \mathrm{C}$ and were equilibrated with $100 \% \quad \mathrm{O}_{2}$. After a 10 -sec oxygenation $\left(100 \% \mathrm{O}_{2}\right)$, the tube was sealed. Following a 10 -min digestion period in a shaking water bath at $37^{\circ} \mathrm{C}$ for 150 $(\mathrm{cpm} / \mathrm{min})$, at the end of third digestion period, acini were then resuspended in fresh medium and aspirated five times in a Pasteur pipette followed by dissociation through the nylon mesh $(150 \mathrm{~mm})$. The suspension was layered onto $4 \%$ BSA. After oxygenation for 2-3 sec, a 1-ml aliquot containing the bile extracts or various concentrations of CCK-8 was added to the tubes, and the tubes were sealed and then dispersed pancreatic acinar cells were incubated for a $30-\mathrm{min}$ at $37^{\circ} \mathrm{C}$. Amylase release into media was measured after a $30-\mathrm{min}$ incubation period. The incubation medium was removed and assayed for amylase activity using the Padebas amylase test (Amylase Test A Shionogi, Shionogi Pharmaceutical Co., Ltd, Osaka, Japan). Amylase release was expressed as the percentage of amylase activity released into the medium vs. total amylase activity and CCK-8 bioactivity was evaluated using the standard curve of amylase release which was expressed as the percentage of amylase activity released into the medium vs total amylase activity $\left(10^{-8}-10^{-12} \mathrm{M}\right)$.

\section{Radioimmunoassay}

Cholecystokinins were measured by radioimmunoassay using anti-CCK antiserum, OAL656, as described by Hashimura et al. ${ }^{15)}$. The recovery rates of CCK-8, CCK-33, and CCK-39 were $100 \%, 100 \%$ and $85 \%$, respectively, by the anti-CCK antiserum developed specifically against the CCK amino-terminus.

\section{Result}



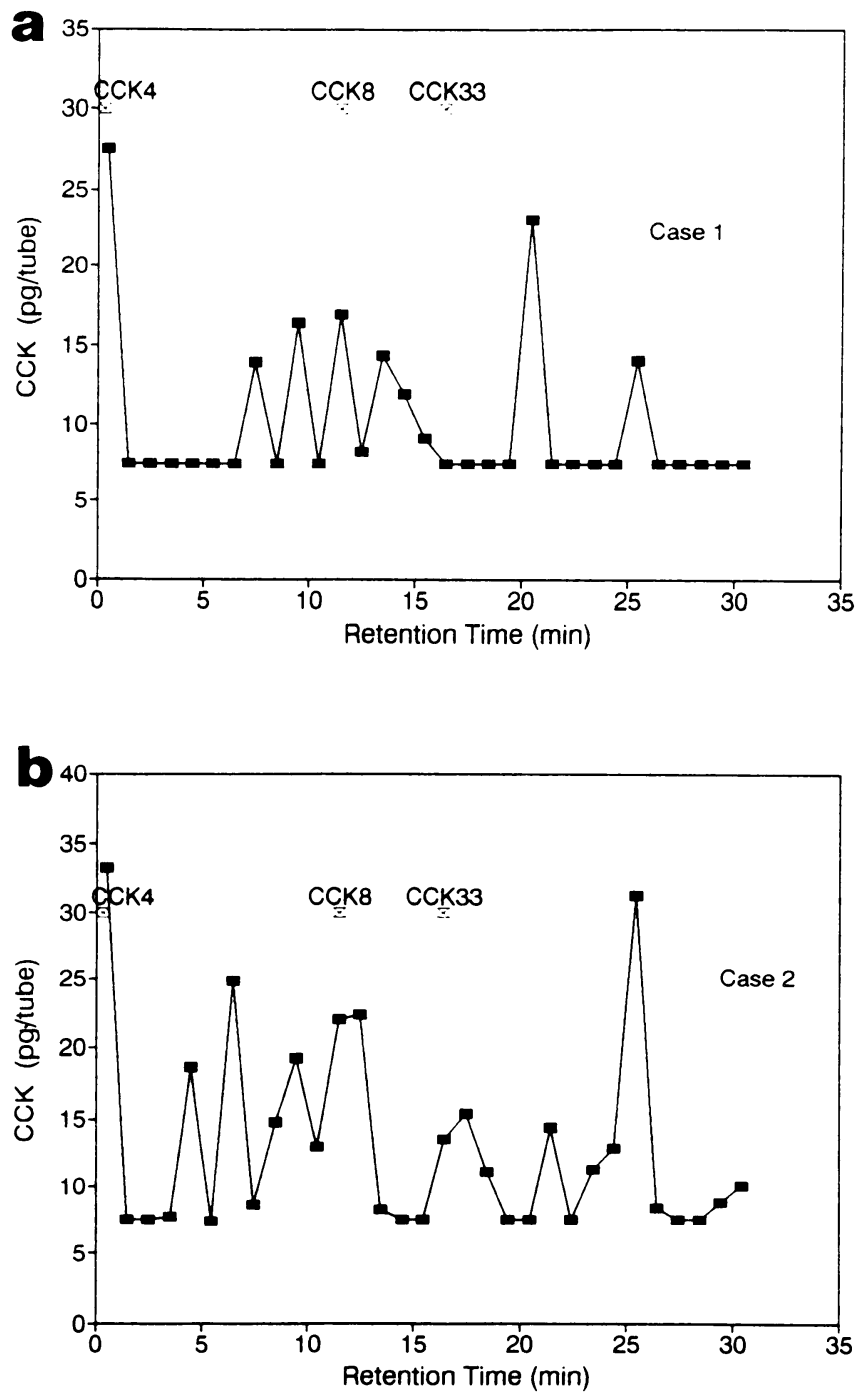

Fig. 2 High performance liquid chromatography (HPLC) elution profiles of CCKs in human bile obtained from patients with obstructive jaundice (upper, lower panel) by radioimmunoassay.

\section{Chromatographic analysis}

Sephadex G-25 elution profiles of ${ }^{125}$ I-CCK-8 and ${ }^{125}$ I-CCK-39 are shown in Fig. 1. Two major radioactive peaks were observed. The first peak corresponded with ${ }^{125}$ I-CCK-39 and the second with ${ }^{125} \mathrm{I}-\mathrm{CCK}-8$. The recovery rates of ${ }^{125} \mathrm{I}-\mathrm{CCK}-8$ and ${ }^{125} \mathrm{I}-\mathrm{CCK}-39$ were 67.8 $\pm 6.1 \%$ and $72.9 \pm 8.7 \%$, respectively.

\section{HPLC analysis}

High performance liquid chromatography (HPLC) elution profiles of CCKs were obtained from human bile from patients with obstructive jaundice. Each fraction of CCK 


\section{HPLC Elution Profiles of Bile CCK Obstructive Jaundice}
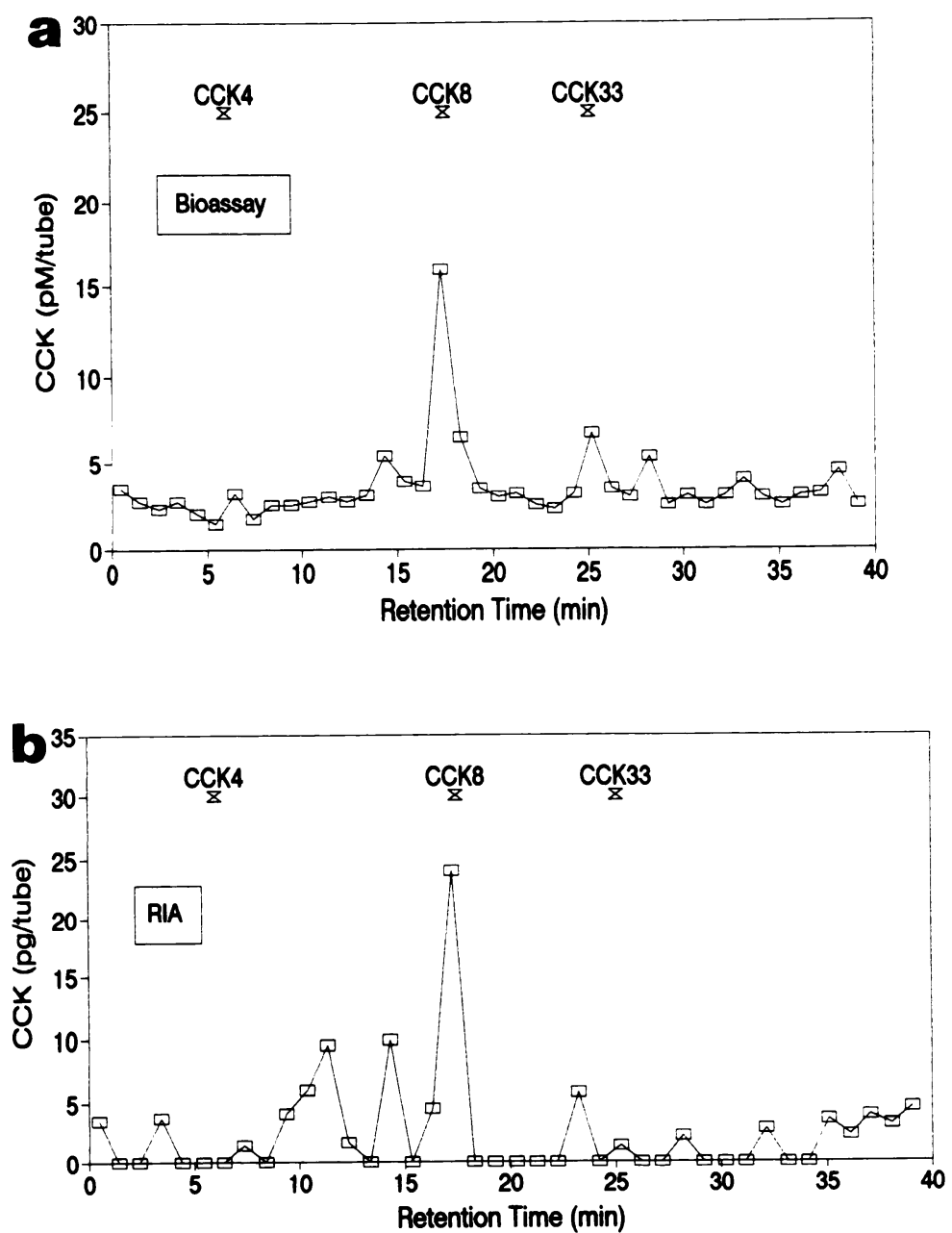

Fig. 3 HPLC elution profiles of CCKs in human bile obtained from patients with obstructive jaundice.

activity was measured by radioimmunoassay (Figs. 2, 3, 4b) and bioassay (Figs. 3, 4a). Several CCK radioimmunoreactive peaks were detected (Figs. 2, 3, 4b). In case 1 (Fig. 2a), CCK-8 was measured by RIA and detected by bioassay. In case 3 (Fig. 3), CCK-8 and CCK-33 were measured by RIA (Fig. 3b) and detected by bioassay (Fig. 3a, Table 1). In case 2 (Fig. 2b), CCK-8 and CCK-33 were measured by RIA, however, CCK-8 could not be detected by bioassay (Fig. 2b, Table 1). The CCK receptor antagonist L-364,718 ( $10 \mathrm{nM}$ ) completely inhibited the bioactivity of CCKs obtained from human bile (Table 1). Therefore the larger molecular forms of CCK were present in bile of patients with obstructive jaundice.

In one patient without obstructive jaundice (case 4 ), CCK-8 was detected by bioassay (Fig. 4) and L-364,718 completely inhibited its bioactivity (Table 1). 

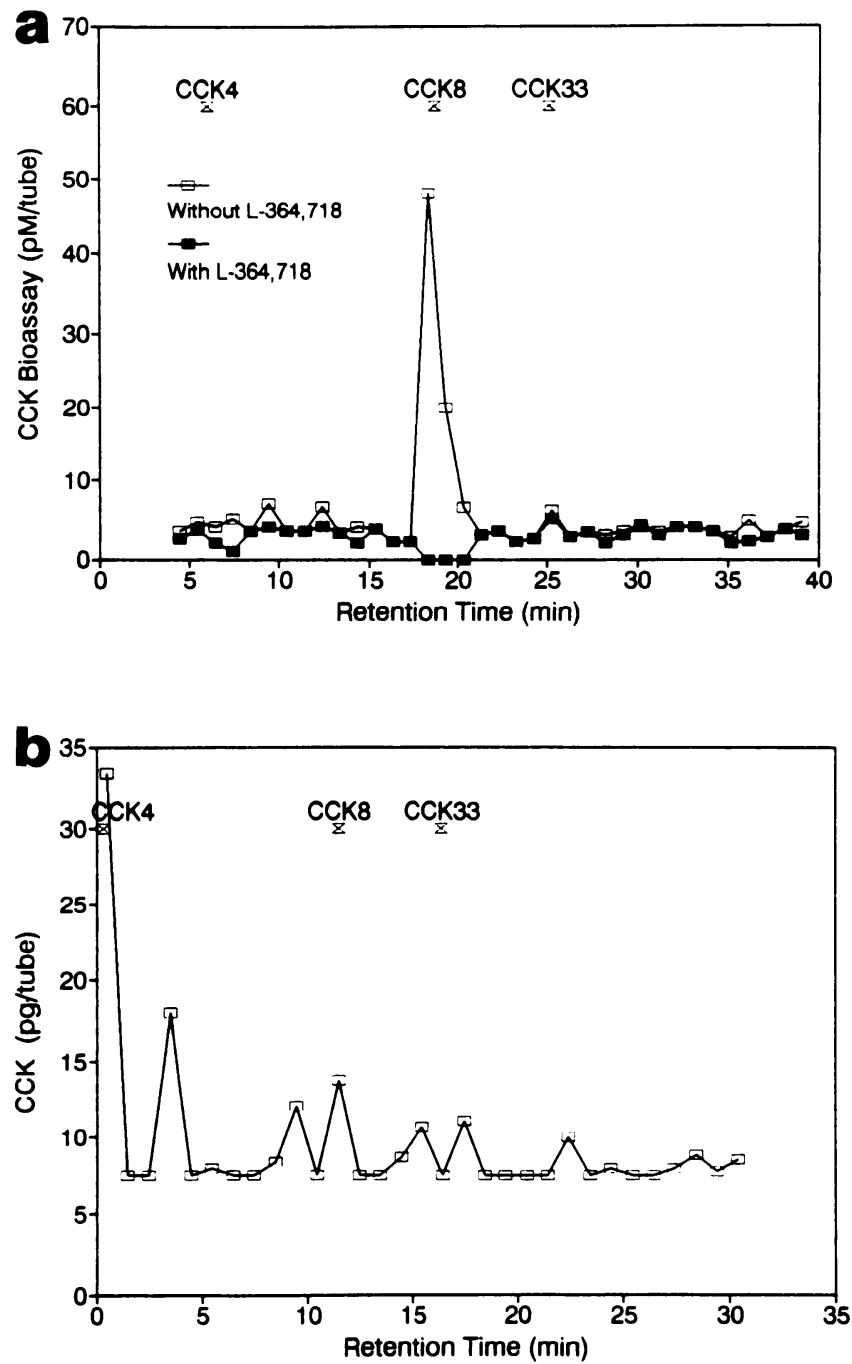

Fig. 4 HPLC elution profiles of CCK in human bile obtained from a patient without obstructive jaundice.

Table 1. Comparison of analysis of four different samples of CCK-8 and CCK-33 extracted from human bile by bioassay system with or without L-364,718 and the radioimmunoassay system.

\begin{tabular}{cccccc}
\hline \multirow{2}{*}{ CASE } & Radioimmunoassay $(\mathrm{pg} / \mathrm{ml})$ & \multicolumn{2}{c}{ Bioassay $(\mathbf{P M})$} & \multicolumn{2}{c}{ Bioassay with. L-364, 718 (PM) } \\
\cline { 2 - 6 } & Total CCK & CCK-8 & CCK-33 & CCK-8 & CCK-33 \\
\hline 1 & - & 18 & N.D. & 0 & N.D. \\
2 & 144.1 & N.D. & 30 & N.D. & 0 \\
3 & 104 & 16 & 6.8 & 0 & 0 \\
4 & 237 & 48 & N.D. & 0 & N.D. \\
\hline
\end{tabular}


The CCK analysis of four different bile samples is summarized in Table 1. Total CCK levels were lower in human bile of patients with obstructive jaundice compared with patients without obstructive jaundice.

There was a good correlation between total CCK radioimmunoreactivity and $50 \mu 1,100 \mu \mathrm{l}$ and $200 \mu \mathrm{l}$ aliquot of bile samples after HPLC isolation $(\mathrm{r}=0.998, \mathrm{p}<0.01)$.

\section{Discussion}

Numerous CCK molecular forms have been characterized in human blood ${ }^{25,26)}$, in canine ${ }^{2)}$, rat $^{27,28)}$ intestinal extracts and in sheep ${ }^{3)}$ and pig $^{4,5)}$ brain extracts. The molecular forms of CCKs in human plasma, however, have not been clearly established. Eberlein et al. ${ }^{25)}$ and Eysselein et al. ${ }^{26)}$. recently reported that CCK-58 is the major molecular form released into plasma circulation in healthy volunteers; CCK- 58 was processed in vitro by plasma, and degradation of CCK-58 could be inhibited by addition of acid. Some circulating hormones are rapidly extracted by the hepatocyte and excreted into bile $e^{3,11,12-14)}$.

The kidney may play a major role in CCK-33 elimination in $\operatorname{dog}^{20)}$, whereas the liver may play a major role in CCK-8 elimination in rat $^{19)}$ and human ${ }^{22)}$. However, another study found that CCK-8 is the major form of CCK excreted into human urine ${ }^{18)}$. Studies of hepatic and renal elimination of various molecular forms of CCK have been controversial. In the present study, we investigated the effect of purification and isolation of CCKs extracted from human bile obtained from patients with or without obstructive jaundice on measurement of CCK by RIA and bioassay. Human bile contains a large amount of bile acids, phospholipids and bilirubin. Eighty to $90 \%$ of phospholipid was extracted by chloroform in the present study, but only $40-50 \%$ of bilirubin and $30 \%$ of bile acids were extracted by chloroform. We could not measure CCKs before purification and isolation of CCKs in human bile, perhaps because the large amounts of bile acids and bilirubin interfered with measurement of CCK by RIA or bioassay.

We were able to directly detect the bioactivity of CCKs in human bile and demonstrated the presence of two biologically active CCK forms, CCK-8 and CCK-33, in human bile. Recently, Miyasaka et al. ${ }^{23)}$ demonstrated that bile acids in human plasma interfere with the bioactivity of CCK. In the present study, the concentration of total bile acids in bile was less than $1 \mu \mathrm{M}$ after purification by HPLC, and at this concentration bile acids presumably did not affect the CCK bioassay system. Some circulating hormones are rapidly extracted by hepatocytes and appear in bile in both intact and metabolized forms. Renston et al. ${ }^{12)}$ reported that most of the insulin in bile was not intact after extraction of ${ }^{125}$ I-insulin secreted into bile by Sephadex G-50 column. In contrast, EGF radioactivity in bile was noted at $10 \mathrm{~min}$ following an intraportal bolus injection of ${ }^{125} \mathrm{I}$-EGF and the concentration of biliary immunoprecipitable EGF was estimated to be approximately $0.5 \mathrm{ng} / \mathrm{ml}^{13)}$. Pentagastrin is also excreted in both intact and metabolized forms in bile using labeled glycine-pentapeptide ${ }^{14)}$. Furthermore, Gores et al. ${ }^{11)}$ found that radiolabeled desulfated CCK-8 and CCK-4 in bile were completely metabolized, but $20 \%$ of the major forms of labeled CCK- 8 in bile were intact labeled octapeptide, and they speculated that the presence of a sulfate on the tyrosine residue partially prevented CCK-8 from processing and therefore allowed some CCK- 8 to be excreted intact into bile. They also concluded that the liver is important in the metabolism of CCK. We detected biologically active CCK-8 in the bile of a patient without obstructive jaundice (case 4). The concentration of biliary 
radioimmunoreactive CCK was estimated to be approximately $100-300 \mathrm{pg} / \mathrm{ml}$. It is unclear why intact CCKs appeared in bile of a patient with obstructive jaundice. Further study is needed to clarify the mechanism involved in the generation of CCK fragments.

Recently, a novel, orally effective, extremely potent nonpeptide CCK receptor antagonist has been reported ${ }^{6,7)}$. L-364,718, a synthetic benzodiazepine derivative, was represented as a potent nonpeptide CCK-A receptor. L-364,718 has been used to characterize the role of CCK in gastrointestinal physiology. Louie et al. reported that L-364,718 was 600 -fold more potent than CR1409 and 2,000,000-fold more potent than proglumide in inhibiting CCK-8-induced amylase release from rat pancreatic acini ${ }^{30)}$. In the present study, bioactivity of CCK in human bile was completely inhibited by L-364,718.

A number of studies have examined clearance of CCKs from the circulation ${ }^{3-11,15-17,21,22)}$. Since the liver is a target tissue of many biologically important molecules, Gores et al. ${ }^{8}$ ' have studied the hepatic uptake of CCK in the isolated, perfused rat liver and a series of radioiodinated and unlabeled CCK peptides. Of the naturally-occurring forms of CCK, large amounts of CCK-8 were extracted $(26 \pm 0.7 \%$ of Bolton-Hunter-labeled CCK-8, 59\% of unlabeled CCK-8) in a single pass through the liver, while CCK-33 was minimally extracted (3.1 $\pm 1.2 \%$ of Bolton-Hunter-labeled CCK-33). Taurocholate at concentrations of 200,446 , and $4460 \mu \mathrm{M}$ significantly decreased labeled CCK-8 in liver extracts ${ }^{8)}$. The half-life of plasma CCK-33 was reported to be $3.3 \mathrm{~min}$ in human ${ }^{9)}$, and CCK-8 is degraded more rapidly than CCK-33 ${ }^{10)}$. An elevation in fasting plasma CCK level has been demonstrated in patients with hepatic cirrhosis ${ }^{21)}$. Taken together, these data suggest that the liver may be the major site of CCK degradation. In our patients with obstructive jaundice the concentration of plasma bile acids was more than $200 \mu \mathrm{M}$. Therefore it is possible that bile acid (taurocholate) inhibited CCK extraction, which resulted in the larger molecular form of CCK being excreted into human bile. We conclude that a large molecular form of CCK specifically appears in bile of patients with obstructive jaundice, compared with patients without obstructive jaundice. The present study is the first to report the purification and isolation of CCKs extracted from human bile of patients with obstructive jaundice.

In conclusion, we examined the effect of purification and isolation of CCKs extracted from human bile on the measurement of CCK by RIA and bioassay. We directly demonstrated that various CCK species, especially CCK-8 and CCK-33, are present in human bile obtained from patients with and without obstructive jaundice. The range of CCK species in human bile were able to be measured by both RIA and bioassay after purification using a Sephadex G-25 column. Furthermore, a large molecular CCK isoform predominantly appeared in bile of patients with and without obstructive jaundice.

\section{Acknowlegements}

We wish to thank Dr. Yoshio Hatta, the former professor of the Second Department of Internal Medicine, Showa University School of Medicine, and Dr. Hiroshi Miyazaki, Kotobuki Pharmaceutical Company, Nagano, Japan, for their thoughtful advice with regard to the present study.

\section{References}

1) Mutt V and Jorpes E: Structure of porcine cholecystokinin-pancreozymin I. Cleavage with thrombin and with trypsin. Eur J Biochem 6 : 156-162 (1968) 
2) Eysselein V, Reeve J Jr, Shively J, Hawke D and Walsh $\mathbf{J}$ : Partial structure of a large canine cholecystokinin (CCK58) : Amino acid sequence. Peptides 3 : 687-691 (1982)

3) Dockray G, Gregory $\mathbf{R}$ and Hutchison $\mathbf{J}$ : Isolation, structure and biological activity of two cholecystokinin octapeptides from sheep brain. Nature $274: 711-713$ (1978)

4) Eng J, Shiina Y, Pan Y. C, Blacher R, Chang M, Stein S and Yalow R: Pig brain contains cholecystokinin octapeptide and several cholecystokinin desoctapeptides. Proc Natl Acad Sci USA 80 : 6381-6385 (1983)

5) Tatemoto $\mathrm{K}$, Jornvall $\mathrm{H}$, Siimesmaa $\mathrm{S}$, Hallen $\mathrm{G}$ and Mutt $\mathrm{V}$ : Isolation and characterization of cholecystokinin-58 (CCK-58) from porcine brain. FEBS Lett $174: 289-293$ (1984)

6) Evanse BE, Bock MG, Rittle KE, Dipardo RM, Whitter WL, Ueber DF, Anderson PS and Freidinger RM : Design of potent orally effective nonpeptidal antagonists for the peptide hormone cholecystokinin. Proc Natl Acad Sci USA 83 : 4918-4922 (1986)

7) Chang RSL and Lotti VJ: Biochemical and pharmacological characterization of an extremely potent and selective nonpeptides: Cholecystokinin receptor antagonist. Proc Natl Acad Sci USA 83 : 4923-4926 (1986)

8) Gores GJ, Larusso NF and Miller LJ : Hepatic processing cholecystokinin peptides. I. Structural specificity and mechanism of hepatic extraction. Am J Physiol 250 : G344-G349 (1986)

9) Lilja P, Fagan CJ, Wiener I, Inoue K, Watson LC, Rayford PL and Thompson JC: Infusion of pure cholecystokinin in humans. Correlation between plasma concentrations of cholecystokinin and gallbladder size. Gastroenterology $83: 256-261$ (1982)

10) Sakamoto T, Fujimura M, Newman J, Zhu X-G, Greeley Jr GH and Thompson JC: Comparison of hepatic eliminating of different forms of cholecystokinin in dogs. Bioassay and radioimmunoassay comparisons of cholecystokinin-8-sulfate and 33-sulfate. J Clin Invest 75 : 280-285 (1985)

11) Gores GJ, Miller LJ and Larusso NF : Hepatic processing of cholecystokinin peptides. II. Cellular metabolism, transport, and biliary excretion. Am J Physiol 250 : G350-G356 (1986)

12) Renston RH, Maloney DG, Jones AL, Hradek GT, Wong KY and Goldfine ID: Bile secretory apparatus: Evidence for a vesicular transport mechanism for protein in the rat, using horseradish peroxidase and (125I) insulin. Gastroenterology 78 : 1373-1388 (1980)

13) Hilaire RJ St and Jones AL : Epidermal growth factor : Its biological and metabolic effects with emphasis on the hepatocyte. Hepatology 2: 601-613 (1982)

14) Varro V, Varga L, Csernar L, Nafradi J, Penke B and Balaspiri L: Hepatic and mesentric metabolism of C-terminal penta-peptide of gastrin in the rat. Part 1. Biliary excretion of labelled glycine-pentapeptide. Acta Hepato-Gastroenterol 20 : 500-505 (1973)

15) Hashimura E, Shimizu F, Nishino T, Imagawa $K$, Tateishi $\mathbf{K}$ and Hamaoka $T$ : Production of rabbit antibody specific for amino-terminal residues of cholecystokinin octapeptide (CCK8) by selective suppression of cross-reactive antibody response. J Immunol Methods 55 : 375-387 (1982)

16) Liddle RA, Goldfine ID and Williams JA : Bioassay of plasma cholecystokinin in rats : Effects of food, trypsin inhibitor, and alcohol. Gastroenterology 87 : 542-549 (1984)

17) Gardner JD and Jackson MJ : Regulation of amylase release from dispersed pancreatic acinar cells. J Physiol 270 : 439-454 (1977)

18) Higashimoto Y, Himeno S, Kuroshima T, Okuno M, Kawamoto H, Tsuji K, Kashimura M, Yamasaki Y, Nagao K, Kanayama $S$ and Tarui $S$ : Immunoreactivity and molecular heterogenity of gastrin and cholecystokinin peptide in the human urine. In : Proceeding of The Ninth Gut Hormone Conferance, Miyoshi A (Eds), Igakutosho-shuppan, Tokyo pp 48-56 (1987) (in Japanese)

19) Doyle JW, Wolfe MM and McGuigan JE: Hepatic clearance of gastrin and cholecystokinin peptide. Gastroenterology 87 : 60-68 (1984)

20) Thompson JC, Fender HR, Ramus NI, Villar HV and Rayford PL : Cholecystokinin metabolism in man and dogs. Ann Surg 182 : 496-504 (1975)

21) Himeno S, Tarui S, Kanayama S, Kuroshima T, Shinomura Y, Hayashi C, Tateishi K, Imagawa K, Hashimura $\mathrm{E}$ and Hamaoka T: Plasma cholecystokinin responses after ingestion of liquid meal and intraduodenal infusion of fat, amino acids, or hydrochloric acid in man: Analysis with region specific radioimmunoassay. $A m J$ Gastroenterol 78 : 703-707 (1983)

22) Kanayama S, Himeno S, Kurokawa M, Shinomura Y, Kuroshima T, Okuno M, Tsuji K, Higashimoto Y, Ikei N, Hashimura E, Tateishi K, Hamaoka $T$ and Tarui S: Marked prolongation in disapprance half-time of plasma cholecystokinin-octapeptide in patients with hepatic cirrhosis. Am J Gastroenterol, 80 : $557-560$ (1985) 23. Miyasaka K, Funakoshi A, Matsumoto M, Nakamura R, Sakamoto S, Sakai H and Kitani K: Bile acids in human plasma interfere with cholecystokinin bioassay using dispersed pancreatic acini. Dig Dis Sci, 36 : 310-316 (1991)

24) Kurabayshi M, Niikawa J, Tanaka S, Akita Y, Hatta Y and Mitamura K : A modulatory role of intraduodenal bile in cholecystokinin release in humans. J Showa Med Assoc 55 : 319-326 (1995) (in Japanese) 
25) Eberlein GA, Eysselein VE, Hesse WH, Goebell $\mathbf{H}$, Schaefer $\mathbf{M}$ and Reeve Jr JR: Detection of cholecystokinin-58 in human blood by inhibition of degradation. Am J Physiol 253 : G477-G482 (1987)

26) Eysselein VE, Eberlein GA, Hesse WH, Schaeffer M, Grandt D, Williams R, Schaeffer M, Goebell H and Reeve Jr JR : Molecular variants of cholecystokinin after endogenous stimulation in humans : a time study. Am J Physiol 258 : G951-G957 (1990)

27) Turkelson CM and Solomon TE: Molecular forms of cholecystokinin in rat intestine. Am J Physiol 259 : G364-G371 (1990)

28) Turkelson CM, Solomon TE and Hamilton $\mathrm{J}:$ A cholecystokinin-metabolizing enzyme in rat intestine. Peptides 11 : 213-219 (1990)

29) Larusso NF : Proteins in bile : how they get there and what they do. Am J Physiol 247: G199-G205 (1984)

30) Louie DS, Liang JP and Owyang C: Characterization of a new CCK antagonist, L-364,718: in vitro and in vivo studies. Am J Physiol 255 : G261-G266 (1988)

[Received February 1, 2000 : Accepted February 15, 2000] 